\title{
Intracranial Suppurations in Africa: Systematic Review
}

\section{Léon Boukassa, Olivier Brice Ngackosso, Sinclair Brice Kinata, Hugues Brieux Ekouele Mbaki}

Department of Surgery, Division of Neurosurgery, Brazzaville Academic Hospital, Brazzaville, Republic of Congo

Email:1boukassalouf@gmail.com

How to cite this paper: Boukassa, L., Ngackosso, O.B., Kinata, S.B. and Mbaki, H.B.E. (2020) Intracranial Suppurations in Africa: Systematic Review. Open Journal of Modern Neurosurgery, 10, 244-253. https://doi.org/10.4236/ojmn.2020.102026

Received: October 24, 2019

Accepted: March 15, 2020

Published: March 18, 2020

Copyright $\odot 2020$ by author(s) and Scientific Research Publishing Inc. This work is licensed under the Creative Commons Attribution International License (CC BY 4.0).

http://creativecommons.org/licenses/by/4.0/

\begin{abstract}
Background: Intracranial suppurations (ICS) due to common causative microorganisms are still an important health problem in Africa. Their management, which has certainly been improved by technological developments, varies according to neurosurgical teams. Objectives: To describe the clinical characteristics, the causative microorganisms, the outcome, and provide relevant data on the current modalities of the care of ICS. Methods: We conducted a systematic review of studies on intracranial suppurations published in Africa between January 2002 and December 2018. We included studies which had at least 6 patients with ICS. Pubmed, Google and Google scholar were searched for relevant studies. A total of 17 studies were found, from which we define the epidemiological aspects, therapeutic, and evolutionary diagnostics. Results: A total of 1166 patients were identified, and they were categorized as follows: 531 cases of abscess, 272 of empyema and 363 of intracranial suppurations with incomplete data (ICSDI). The average age in ICSDI was 10.9 years. In abscesses and empyema, $75 \%$ of patients were under 40 years. There was a male predominance of 2.4 to 1 . These intra-cranial suppurations in general complicated mainly loco-regional infections. The classic triad was dominated by headache $(66.5 \%)$, fever $(59.4 \%)$ and neurological deficits (46.1\%). The CT rarely associated with the MRI, had shown a predominance of supra-tentorial sites $(92.5 \%)$ of which $37.5 \%$ was in frontal region. Of the 380 microorganisms isolated, Gram positive represented $68.9 \%$, Gram negative $17.7 \%$ and anaerobic $13.4 \%$. The treatment was medico-surgical $(79.5 \%)$. It associated a triple antibiotherapy and a trepano-puncture. It had achieved healing in $88.2 \%$ of which $20.4 \%$ had sequelae. Case fatality rate was $11.8 \%$. Conclusion: ICS constitute during this century, a health problem whose solution passes by the adequate treatment of loco-regional infections, their main sources.
\end{abstract}

\section{Keywords}

Intracranial, Suppuration, Abscess, Empyema 


\section{Introduction}

Intracranial suppurations (ICS) are intracranial purulent collections, of infectious origin, developing in intracerebral (abscess) or in the sub or epidural (empyema) spaces [1]. When the infective agents are parasitic and mycotic, which are more and more frequent with immune-depressed states, their treatments are mainly medical, and for the non-specific bacterial etiologies, they are medico-surgical emergencies [1] [2]. The management of the latter, which has benefited from the contribution of new medical imaging techniques and recent therapeutic developments (antibiotic therapy and surgical techniques), has generally had a positive impact on their once poor prognosis. The review of the literature on these conditions in Africa goes back to the work of Loembe [3] in 1997. On the basis of essentially hospital epidemiological data, it showed an incidence of between $2 \%$ and $5 \%$, the predominance of young male subjects. These were often the complications of loco-regional infections, and Bergman's classic clinical triad was found in only about $25 \%$ of patients. Arteriography was the gold standard for the diagnosis. The causative microorganisms were mainly Staphylococcus and Gram-negative bacilli in sub-Saharan Africa and Streptococcus outside this area. The treatment was medico-surgical. It was a bi or tri antibiotic therapy associated with evacuation of the pus pocket. The mortality was between $11.5 \%$ and $43 \%$ depending on the series.

More than 20 years after this work, Africa has seen an improvement in its neurosurgical demography [4] and its equipment in modern medical imaging. But she still faces these conditions that have kept their gravity. We are initiating this work, in the light of these modest health advances, to bring out their current characteristics in Africa.

\section{Methods}

A systematic review of studies on intracranial suppurations in Africa published from January 2002 to December 2018 was conducted. Pubmed, Google and Google scholar were searched for relevant studies as well as some websites of universities like Cheik Anta Diop in Senegal and Marrakech in Morocco. The search terms were: abscess of the brain, intracranial empyema and intracranial suppuration associated with the word Africa. The selected works were those published in the period of study, in French or English, and with more than six cases in which data on age and sex were found. For the authors having published works on the same subject, during this period, we selected the one where the number was the most important. We excluded studies on specific parasitic, mycotic and bacterial etiologies, and those in which the cranial suppurations were cited in the complications of certain pathologies.

Seventeen papers (15 papers and 2 theses) from 11 African countries were collected. They were eight studies from West Africa (Côte d'Ivoire [5], Senegal [6] [7] [8], Burkina Faso [9], Mali [10] Nigeria [11], Ghana [12]); 02 studies in Central Africa (Cameroon [13], Gabon [14]); 03 studies in Southern Africa 
(South Africa [15] [16] [17]); and 03 studies in the Maghreb (Morocco [18] [19] [20]). These studies were classified into three groups: abscesses, empyemas, and the insufficient data intracranial suppuration group (ICSDI), when the share of each of these two entities was not clear in the study.

All data were entered into a Microsoft Office 2010 Excel spreadsheet. Epidemiological, clinical, paraclinical, therapeutic and evolutionary parameters were analyzed. Some frequencies were compared by the statistical calculation method $\mathrm{U}$ and the value of $\mathrm{p}$ fixed at 0.05 .

\section{Results}

From the 17 studies, 1166 patients were identified. Publications on abscesses accounted for 531 cases, 272 cases of empyema and 363 cases for ICSDI.

\subsection{Epidemiological Aspects}

The average age in ICSDI, calculated from three studies $(\mathrm{n}=93$ cases) mainly pediatric, was 10.9 years with extremes of 1 month to 18 years. In abscesses and empyema, the available data were only proportional to the proportion of young patients. Thus, in abscesses the proportion of patients under 30 years of age represented 54.5\% $(\mathrm{n}=328)$ and that of patients under 40 in empyema was $80.4 \%(\mathrm{n}=87)$.

The overall sex ratio was 2.4 with no significant difference across the three groups.

The provenance of patients was for 74 cases, departments of ORL, pediatric and infectious diseases. The numbers for each service were not specified. These patients remained hospitalized for a period ranging from 1 to 180 days.

The origin of these infections is reported in Table 1.

Table 1. Origin of infections.

\begin{tabular}{|c|c|c|c|c|c|c|c|c|}
\hline \multirow{2}{*}{ Infection's origin } & \multicolumn{2}{|c|}{ UICS $(n=363)$} & \multicolumn{2}{|c|}{$\mathrm{A}(\mathrm{n}=474)$} & \multicolumn{2}{|c|}{$E(n=241)$} & \multicolumn{2}{|c|}{ Total $(n=1032)$} \\
\hline & $\mathrm{N}$ & $\%$ & $\mathrm{~N}$ & $\%$ & $\mathrm{~N}$ & $\%$ & $\mathrm{~N}$ & $\%$ \\
\hline Identify & 277 & 76.3 & 325 & 68.6 & 142 & 59 & 844 & 81.7 \\
\hline Loco-regional & 262 & 72.1 & 319 & 67.3 & 141 & 58.5 & 822 & 79.6 \\
\hline Sinusitis & 75 & 20.6 & 45 & 9.5 & 69 & 28.6 & 289 & 28 \\
\hline Otitus & 31 & 8.5 & 65 & 13.7 & 15 & 6.2 & 111 & 10.7 \\
\hline Inf. Scalp \& Face* & 50 & 13.7 & 10 & 2.1 & 2 & 0.8 & 62 & 6.2 \\
\hline Traumatic & 58 & 16 & 117 & 24.7 & 14 & 5.8 & 189 & 18.3 \\
\hline Meningitus & 44 & 12.1 & 32 & 6.7 & 13 & 5.3 & 89 & 8.6 \\
\hline Post operatory & 4 & 1.1 & 9 & 1.9 & 18 & 7.4 & 31 & 3 \\
\hline Non specified ${ }^{\star *}$ & & - & 41 & 8.6 & 10 & 4.1 & 51 & 4.9 \\
\hline Métastatic & 15 & 4.1 & 6 & 1.2 & 1 & 0.4 & 22 & 2.1 \\
\hline Non identified & 86 & 23.7 & 149 & 31.4 & 99 & 41 & 188 & 18.3 \\
\hline
\end{tabular}

${ }^{\star}$ Inf. Scalp \& face: Infection of scalp and face. ${ }^{*}$ Not specified: Locoregional infection unspecified. 


\subsection{Clinical Aspects}

The consultation time was on average 80 days with extremes ranging from 1 to 180 days for 626 cases.

The type of onset was, on a staff of 178 patients, brutal in $34.2 \%$ patients and progressive in $65.7 \%$.

The clinical signs are grouped in Table 2 .

The morphological assessment, in front of these clinical pictures, was made of CT alone in 11 works and, combined with MRI in 5 others. The locations of these suppurated collections are given in Table 3.

The unilateral or bilateral localization had been fully specified only by two authors on abscesses and empyema, for a staff of 296 patients. Single locations predominated in more than 3 out of 4 cases.

On the additional blood tests, HIV serology was positive in $4.8 \%$ out of a total of 124 cases tested. Hyperleukocytosis, elevation of $\mathrm{C}$ reactive protein and acceleration of sedimentation rate (SR) were noted in approximately $70 \%$.

The analysis of pus allowed the isolation of microorganisms in 33.9\%. The average number of isolated microorganisms per sample is 1.9 in general. It varies

Table 2. Clinical signs.

\begin{tabular}{ccccccccc}
\hline \multirow{2}{*}{ Signs } & \multicolumn{2}{c}{ UICS $(\mathrm{n}=363)$} & $\mathrm{A}(\mathrm{n}=364)$ & $\mathrm{E}(\mathrm{n}=272)$ & \multicolumn{2}{c}{ Total $(\mathrm{n}=999)$} \\
\cline { 2 - 8 } & $\mathrm{n}$ & $\%$ & $\mathrm{n}$ & $\%$ & $\mathrm{n}$ & $\%$ & $\mathrm{n}$ & $\%$ \\
\hline Headache & 190 & 52.3 & 273 & 75 & 202 & 74.2 & 665 & 66.5 \\
Fever & 185 & 51 & 225 & 61.8 & 184 & 67.6 & 594 & 59.4 \\
Motor deficit & 151 & 41.6 & 184 & 50.5 & 125 & 46 & 461 & 46.1 \\
Comitial crisis & 111 & 30.5 & 46 & 12.6 & 125 & 45.9 & 282 & 28.2 \\
Loss of consciousness & 98 & 27 & 92 & 25.2 & 119 & 43.7 & 309 & 31 \\
Meningeal Syndrome & 88 & 24.2 & 53 & 14.5 & 37 & 13.6 & 178 & 17.8 \\
Bergman Triad & 52 & 14.3 & - & - & 40 & 14.7 & 929.2 & \\
\hline
\end{tabular}

The Bergman triad associates the syndrome of intracranial hypertension, the infectious syndrome and the signs of neurological focus.

Table 3. Locations of suppurated collections.

\begin{tabular}{ccccccccc}
\hline \multirow{2}{*}{ Topography } & \multicolumn{2}{c}{ UICS $(\mathrm{n}=367)$} & $\mathrm{A}(\mathrm{n}=447)$ & $\mathrm{E}(\mathrm{n}=99)$ & \multicolumn{2}{c}{ Total $(\mathrm{n}=913)$} \\
\cline { 2 - 9 } & $\mathrm{n}$ & $\%$ & $\mathrm{n}$ & $\%$ & $\mathrm{n}$ & $\%$ & $\mathrm{n}$ & $\%$ \\
\hline Supratentorial & 343 & $\mathbf{9 3 . 4}$ & $\mathbf{4 0 8}$ & $\mathbf{9 1 . 2}$ & $\mathbf{9 4}$ & $\mathbf{9 4 . 9}$ & $\mathbf{8 4 5}$ & $\mathbf{9 2 . 5}$ \\
Frontal & 172 & 46.8 & 151 & 33.8 & 20 & 20.2 & 343 & 37.5 \\
Parietal & 36 & 9.8 & 98 & 21.9 & 27 & 27.2 & 161 & 17.6 \\
Temporal & 77 & 20.1 & 58 & 12.9 & 8 & 8 & 143 & 15.6 \\
Inter-hemispheric & 52 & 14.1 & - & & 25 & 25.2 & 77 & 8.4 \\
Temporo-parietal & - & & 31 & 6.9 & - & & 31 & 3.4 \\
Occipital & 6 & 1.6 & 21 & 4.7 & - & & 27 & 7.4 \\
Fronto-parieto-temporal & - & & - & & 14 & 14.1 & 14 & 1.5 \\
Infratentorial & 24 & $\mathbf{6 . 5}$ & $\mathbf{3 9}$ & $\mathbf{8 . 7}$ & $\mathbf{5}$ & $\mathbf{5}$ & $\mathbf{6 8}$ & $\mathbf{7 . 4}$ \\
\hline
\end{tabular}


between a germ per sample for empyemas and 2.25 germs for abscesses. These poly-microbial infections were found in 56 samples. Isolated sprouts are reported in Table 4.

Of the 380 isolated microorganisms, Gram positive represented 68.9\%, Gram negative $17.7 \%$ and anaerobic $13.4 \%$. The presence of Multi-bacterial infections explains the fact that the isolated germs are superior to positive bacteriological examinations. Of 51 isolated anaerobic microorganisms, 27 were specified. These were Clostridia and Bacteroides in 8 cases each, Proprionebacterium and Peptostreptococcus in 4 cases each and Nocardia: 3 cases.

\subsection{Treatment and Outcome}

The type of treatment (medical exclusive or medico-surgical) instituted was specified only for empyemas and abscesses. It was mainly medical-surgical and represented $79.5 \%$ overall.

Empirical antibiotic therapy prescribed in most cases, mainly included associations. The third-generation cephalosporin and metronidazole were associated with either aminoglycoside in $41.1 \%$, fluoroquinolone in $39.1 \%$. In $9.4 \%$ the cephalosporin was associated with phenicol.

Other drugs were used. These were antiepileptic drugs prescribed in $48.2 \%$ $(\mathrm{n}=286)$ and steroids in $39.8 \%(\mathrm{n}=186)$.

The delay in surgical management was between a few hours and 11 days according to two authors. The surgical treatment, carried out on 463 patients,

Table 4. Isolated germs.

\begin{tabular}{|c|c|c|c|c|c|c|c|c|}
\hline \multirow{2}{*}{ Germs } & \multicolumn{2}{|c|}{ UICS $(\mathrm{n}=115)$} & \multicolumn{2}{|c|}{$\mathrm{A}(\mathrm{n}=335)$} & \multicolumn{2}{|c|}{$E(n=136)$} & \multicolumn{2}{|c|}{ Total $(\mathrm{n}=586)$} \\
\hline & $\mathrm{n}$ & $\%$ & $\mathrm{n}$ & $\%$ & $\mathrm{n}$ & $\%$ & $\mathrm{n}$ & $\%$ \\
\hline Positive test & 50 & 43.4 & 125 & 37.3 & 24 & 17.6 & 199 & 33.9 \\
\hline Gram+ & \multicolumn{2}{|c|}{35} & \multicolumn{2}{|c|}{209} & \multicolumn{2}{|c|}{18} & \multicolumn{2}{|c|}{262} \\
\hline Cocci+ & \multicolumn{2}{|c|}{3} & \multicolumn{2}{|c|}{92} & \multicolumn{2}{|c|}{-} & \multicolumn{2}{|c|}{95} \\
\hline Streptococcus & \multicolumn{2}{|c|}{7} & \multicolumn{2}{|c|}{60} & \multicolumn{2}{|c|}{6} & \multicolumn{2}{|c|}{73} \\
\hline Staphylococcus & \multicolumn{2}{|c|}{19} & \multicolumn{2}{|c|}{49} & \multicolumn{2}{|c|}{6} & \multicolumn{2}{|c|}{74} \\
\hline Other Gram+ & \multicolumn{2}{|c|}{6} & \multicolumn{2}{|c|}{8} & \multicolumn{2}{|c|}{6} & \multicolumn{2}{|c|}{20} \\
\hline Gram- & \multicolumn{2}{|c|}{13} & \multicolumn{2}{|c|}{48} & \multicolumn{2}{|c|}{6} & \multicolumn{2}{|c|}{67} \\
\hline Klebsiella & \multicolumn{2}{|c|}{4} & \multicolumn{2}{|c|}{7} & \multicolumn{2}{|c|}{4} & \multicolumn{2}{|c|}{15} \\
\hline Protéus & \multicolumn{2}{|c|}{1} & \multicolumn{2}{|c|}{14} & & & & \\
\hline E coli & & - & & & & & & \\
\hline Enterobacter & & 2 & & & & & & \\
\hline Pseudomonas & & 2 & & & & & & \\
\hline Citrobacter & & 2 & & & & & & \\
\hline Acinetobacter & & 1 & & & & & & \\
\hline Other Gram- & & 1 & & & & & & \\
\hline Anaerobes & & 26 & & & & & & \\
\hline Association & & 6 & & & & & & \\
\hline
\end{tabular}


proceeded mainly to aspiration of the pus by trepan-puncture in $71.8 \%$, stereotaxis $6 \%$ and bone flap (5.8\%). Excision of the lesion was performed in about $12 \%$ and ventricular derivation in $0.4 \%$.

The treatment of the entrance door was performed in $19.4 \%(n=170)$.

The evolution following the treatment is recorded in Table 5.

Details on the type of sequelae had been given for only 93 cases. They were dominated by motor deficit in $61.3 \%$, epilepsy in $32.2 \%$ and other types of sequelae (hypoacusis, psychic retardation, irritability) in $6.5 \%$. Their association was not specified.

\section{Comments}

Since the beginning of this century, more and more African countries have been equipped with new medical imaging techniques (CT and MRI). These tools have contributed to improving the management of intracranial conditions, including ICS. To this has been added the increase in neurosurgical demography in this same part of the world, with more and more active teams [4]. These two improvements were the reasons that allowed us to retain the work of the ICS, published from this period, especially since the last work on the general review of these diseases going back more than 20 years.

The only study that reported the incidence of this condition was that of Anwary [16] in South Africa (1/1,000,000 inhabitants/year), the other reported incidences were mostly hospitable. Male patients under the age of 40 were the most affected by this condition as already noted in older African studies [3] [21]. A single study on empyema was an exception on the male predominance of this condition with a sex ratio of 0.8 [10].

ICS complicate mainly loco-regional infections, but also those located at a distance. This explains the fact that patients were first hospitalized in the pediatric, infectious diseases or ORL departments. Referral to neurosurgery services was made only after the morphological assessment. Loco-regional infections and particularly ORL infections (30\%) were the most common sources of these ICS. These were sinusitis (18.7\%) and ear infections (11.2\%), which rank first and

Table 5. Evolution after treatment.

\begin{tabular}{lcccccccc}
\hline \multirow{2}{*}{ Evolution } & \multicolumn{2}{c}{$\mathrm{UICS}(\mathrm{n}=171)$} & \multicolumn{2}{c}{$\mathrm{A}(\mathrm{n}=343)$} & $\mathrm{E}(\mathrm{n}=215)$ & \multicolumn{2}{c}{ Total $(\mathrm{n}=729)$} \\
\cline { 2 - 9 } & $\mathrm{n}$ & $\%$ & $\mathrm{n}$ & $\%$ & $\mathrm{n}$ & $\%$ & $\mathrm{n}$ & $\%$ \\
\hline Death & 31 & 18.1 & 28 & 8.1 & 27 & 12.5 & 86 & 11.8 \\
Healing & 140 & 81.8 & 315 & 91.9 & 188 & 87.4 & 643 & 88.2 \\
Without sequelae & 114 & 66.6 & 222 & 64.7 & 158 & 73.5 & 494 & 67.7 \\
Sequelae & 26 & 15.2 & 93 & 27.1 & 30 & 13.9 & 149 & 20.4 \\
Non specified & 10 & 5.8 & 26 & 7.6 & 20 & 9.3 & 56 & 7.7 \\
-Epilepsy & 7 & 4.1 & 18 & 5.2 & 5 & 2.3 & 30 & 4.1 \\
-Motor deficit & 3 & 1.7 & 49 & 14.3 & 5 & 2.3 & 57 & 7.8 \\
-Others & 6 & 3.5 & - & & - & & 6 & 0.8 \\
\hline
\end{tabular}


third respectively in these sources of infection overall. This same distribution was observed in the countries of West Africa, Central Africa and South Africa. In Morocco, on the other hand, otitis and sinusitis occupied first and third place respectively. Cranio-encephalic injuries ranked second overall (17.5\%) and in any region of Africa. They were already important in the last century in Senegal [21]. The increase in the number of victims of road accidents and urban violence [16] explained among other things the place of these traumas.

The correlation between the microorganism found at the presumed portal of entry and that of intracranial suppuration was not reported in most studies. Boumediane [18], who looked for it in 10 patients, was inconclusive. Taking this into account, it seems fairer to speak of a probable gateway. From these loco-regional foci or distant foci, the intracranial location of these infections among other mechanisms, were thrombophlebitis, the septic embolus [3].

The delay between the onset of signs, which is often progressive (65.7\%), and the morphological diagnosis was on average 80 days. Its importance was due to the diagnostic difficulties. Antibiotic therapy, often prescribed during this period, was at the origin of the modifications of the clinical pictures and the frequent negativity of the bacteriological examinations of pus [7] [15] [18]. The delayed diagnosis was also a factor of bad evolution during these ICS according to Sichiziya [15].

The clinical signs were dominated by the triad made of headache (66.5\%), fever (59.4\%) and neurological deficit (46.1\%). Their association, however, was not well specified. The Bergman triad, which associates them, was only reported in $9.2 \%$ of cases by taking all the studies. The difference between the large percentages of these signs taken in isolation and their association is probably due to the fact that their appreciation was made for certain authors at the time of their admission to the specialized service. These associations, which were surely present in the history of the disease of these patients, could have been modified by the antibiotherapy often prescribed before the specialized treatment.

New medical imaging techniques have largely supplanted arteriography, which was once the morphological examination of choice [3]. Essentially represented by CT and MRI, they allow a more precise description of these suppurations. But, they must be interpreted taking into account the clinical context because the images characterizing them make also discuss other affections like encephalic metastases and gliomas. The importance of CT in the diagnosis of these conditions is found in this analysis. Few authors have used MRI, let alone its flow sequences and spectrometry. The role of the latter in differentiating abscesses from other mostly tumor lesions was used by authors such as [18]. These new examinations had made it possible to note the predominance of abscesses compared to empyemas, as already reported by Loembe [3]. The tentorial location of the lesions (92.5\%), often unique (81\%) was more found than the infratentorial. Abscess-empyema associations have been reported, including 5 cases in Boumediane's thesis [18] and 7 cases in Ouiminga [7]. 
Biologically, the field of immunodepression to HIV was found in $4.8 \%$ of cases, which is not in line with the fears expressed by Loembé [3]. Disruption of inflammatory markers (blood account, SR and CRP) during ICS is common. These are good monitoring parameters for these patients. However, no study had used the assay of Pro-calcitonin as an inflammatory marker. It would be able to determine the active nature of an infection in general [22].

The bacteriological study of ICS pus appears as the weak point of the management of these affections. Isolation of microorganisms was still low (33.9\%). The reasons were, among others, long preoperative antibiotic therapy; the conditions for sampling, storing and transporting pus and finally, the insufficient equipment of our laboratories [7]. Of the 380 bacteria isolated, Gram-positive Cocci (68.9\%) were predominant, followed by Gram-negative Bacillus (17.7\%) and anaerobic bacteria (13.4\%). Bacterial associations were found in 56 bacteriological examinations of pus. The identification of the microorganisms showed the predominance of Streptococci and Staphylococci, which were the most frequent in Loembe's analysis [3]. However, he noted a predominance of Staphylococci in Africa south of the Sahara and that of Streptococci in other African regions.

The treatment of these CIS was mainly medical-surgical. On the medical side, it was always a combination of antibiotics, justified by the bacterial associations mentioned above. Several associations were used "empirically". The most common were third generation cephalosporin combinations - aminoglycoside - metronidazole $(41.1 \%)$ and third generation cephalosporin - fluoroquinolones metronidazole (39.1\%). The duration of this antibiotic therapy ranged from 21 to 90 days. Its prescription as well as its adaptation after identification of the microorganism was not detailed in these different works. Medical treatment also included anticomitials and corticosteroids. The surgical component of this treatment consisted of the evacuation of the purulent collection. Realized sometimes after a long delay (up to 11 days in some cases), it used mainly the technique of trepano-puncture. The stereotactic procedure was rarely a remedy. This is certainly an interesting alternative because it can be achieved even in the early stages of the disease. The biopsy obtained by this means may allow early identification of microorganisms, and thus the initiation of a targeted antibiotic therapy. This procedure will avoid the need for costly surgery in our countries. It remains, however, unavailable in several African countries. Considered as current, by many authors, the excision of the hull of the abscess was indicated in case of the existence of a foreign body in the abscess [18].

From a preventive point of view, the adequate treatment of the frequent sources of these infections (ORL infections, for example), can lead to a satisfactory reduction of these ICS. Indeed, Anwary [16] in South Africa shows an increase in the incidence of sinusitis-related ICS between June and August (Winter) period when sinusitis is most common.

These treatments resulted in patient recovery in $88.2 \%$. Of these, $20.4 \%$ were 
with sequelae. The latter had been well detailed only in one study [18]. Deaths accounted for $11.8 \%$. The factors predicting this fatal evolution are the important disorders of conscience and the delay diagnosis [11] [15] [18]. Although this lethality has generally decreased in all compiled work, it is still high compared to that observed in developed countries [23].

\section{Conclusion}

ICS are still a health problem in Africa because of the high lethality they cause. The information obtained from this study, highlights the need to deepen it by conducting a multicenter study. The latter, based on a rigorous methodology, will allow us, in our opinion, to draw the appropriate conclusions on these conditions.

\section{Conflicts of Interest}

The authors declare no conflicts of interest regarding the publication of this paper.

\section{References}

[1] Leys, D. (2001) Abcès cérébraux et empyèmes intracrâniens. In: Neurologie, EncyclMédChir, Elsvier, Amsterdam, 7 p.

[2] Laurichesse, J.-J., Souissi, J. and Leport, C. (2009) Abcès du cerveau. EMC, Elsevier Masson SAS, Paris, Traité de Médecine Akos, 4-0975.

https://doi.org/10.1016/S1634-6939(09)45383-3

[3] Loembe, P.M., Okome-Kouakou, M. and Alliez, B. (1997) Les suppurations collectées intracrâniennes en milieu africain. Médecine Tropicale, 5, 186-194.

[4] El Kahamlichi, A. (2001) Qfricanneurosurgery: Current Situation, Priorities and Needs. Neurosurgery, 48, 1344-1347. https://doi.org/10.1227/00006123-200106000-00034

[5] Broalet, E., N’dri Oka, D., Eholie, S.P., Guillao-Lasme, E.B., Varlet, G. and Ba Zeze, V. (2002) Abces et empyemesintracraniens chez l'enfant observes à Abidjan (Côte d'Ivoire). African Journal of Neurological Sciences, 21, 38-41. https://doi.org/10.4314/ajns.v21i1.7517

[6] Ba, M.C., Kachungunu, C.M., Mudekereza, P.S., et al. (2014) Les suppurations collectées intracrâniennes à Dakar: A Propos De 125 Cas. Journal de Neurochirurgie, 19, 17-25.

[7] Ouiminga, H.A.K., Thiam, A.B., Ndoye, N., et al. (2014) Les empyèmes intracrâniens: Aspects épidémiologiques, cliniques, paracliniques et thérapeutiques. Étude rétrospective de 100 observations. Neurochirurgie, 60, 299-303. https://doi.org/10.1016/j.neuchi.2014.06.015

[8] Passeron, H., Sidy Ka, A., Diakhate, I. and Imbert, P. (2010) Suppurations intracrâniennes à porte d'entrée otorhinolaryngologique chez l'enfant au Sénégal. Archives de pédiatrie, 17, 134-140. https://doi.org/10.1016/j.arcped.2009.11.001

[9] Kabré, A., Zabsonré, S., Diallo, O. and Cissé, R. (2014) Prise en charge médicochirurgicale des abcès du cerveau à l'ère du scanner en Afrique sub-saharienne: $\mathrm{A}$ propos de 112 cas. Neurochirurgie, 60, 249-253. https://doi.org/10.1016/j.neuchi.2014.06.011 
[10] Diallo, M., Traore, Y., Faye, M., Coulibaly, A., Kanikomo, D. and Diallo, O. (2017) Les empyèmes intracrâniens: aspects diagnostiques et thérapeutiques dans le service de neurochirurgie du chu Gabriel Toure à propos d'une série de 32 cas. La Revue Santé du CAMES, 5, No. 2.

[11] Chikani, M.C., Mezue, W., Okorie, E., Mbachu, C., Ndubisi, C. and Chikani, U.N. (2017) Subdural Empyema: Clinical Presentations and Management Options for an Uncommon Neurosurgical Emergency in a Developing Country. Nigerian Journal of Clinical Practice, 20, 1221-1225.

http://www.njcponline.com/text.asp?2017/20/10/1221/219519

https://doi.org/10.4103/njcp.njcp_340_16

[12] Dakurah, T.K., Iddrissu, M., Weprba, G., et al. (2006) Hemispheric Abscess Brain. A Review of 46 Cases. West African Journal of Medicine, 25, 126-129. https://doi.org/10.4314/wajm.v25i2.28262

[13] Djientcheu, V.P., Mouafo, T.F., Esiene, A., et al. (2013) Intracranial Suppurations in the African Child: A Severe But Preventable Complication. Child s Nervous System, 29, 119. https://doi.org/10.1007/s00381-012-1930-6

[14] Miloundja, J., Bamba, J.S., Mouba, J.F., et al. (2011) Complications cranioencéphaliques des sinusites bactériennes chez l'enfant et l'adolescent: Etude de huit cas vus à Libreville (Gabon). Cahiers d'études et de recherche francophones/Santé, 21, 215-220. https://doi.org/10.1684/san.2011.0275

[15] Sichizya, K., Fieggen, G., Taylor, A. and Peter, J. (2005) Brainabscesses-the Groote Schuurexperience, 1993-2003. South African Journal of Surgery, 43, 79-82.

[16] Anwary, M.A. (2015) Intracranial Suppuration: Review of an 8-Year Experience at Umtata General Hospital and Nelson Mandela Academic Hospital, Eastern Cape. South African Medical Journal, 105, 642-647. https://doi.org/10.7196/SAMJnew.7882

[17] Thobejane, E.K. (2012) The Outcome of Intracranial Subdural Empyema at Steve Biko Academic Hospital: Retrospective Study. Master of Medicine, Neurosurgery Faculty of Health Sciences University of Pretoria, Pretoria.

[18] Boumediane, E.M. (2016) La prise en charge des suppurations Intracrâniennes "A propos de 170 cas” au service de Neurochirurgie CHU Mohamed VI Marrakech. Thèse Med Marrakech.

[19] Baiz, Y., Lmejjati, M. and Ait Benali, S. (2016) Prise en charge des suppurations intracrâniennes (A propos de 88 cas) Service de Neurochirurgie. Hôpital Ibn tofail. CHU Mohammed VI. Marrakech.

[20] Hassani, F.D., El Fatemi, N., Moufid, F., et al. (2014) Abcès encéphaliques: Prise en charge, à propos d'une série de 82 cas. Pan African Medical Journal, 8, 110.

https://doi.org/10.11604/pamj.2014.18.110.2247

[21] Alliez, B., Ducolombier, A. and Gueye, L. (1992) Les suppurations collectées intracrâniennes étude de 64 observations anatomo-cliniques abcès: 44 cas, empyème sous-dural: 16 cas, empyème extra-dural: 4 cas. Médecine dAfrique noire électronique, 39, 377-382.

[22] Ba, K.L., Carballo, S. and Harbarth, S. (2013) Procalcitonine: Doser ou ne pas doser? Revue Médicale Suisse, 9, 1881-1885.

[23] Nathoo, N., Naadvis, S.S., Van Dellen, J.R. and Gows, E. (1999) Intracranial Subdural Empyemas in the Era of Computed Tomography: A Review of 699 Cases. Neurosurgery, 44, 529-535. https://doi.org/10.1097/00006123-199903000-00055 